\title{
LA ANTROPONIMIA DE LA NOBLEZA LEONESA PLENOMEDIEVAL. UN ELEMENTO DE CONSTRUCCIÓN DE IDENTIDAD Y MEMORIA NOBILIARIA
}

\author{
Inés Calderón Medina ${ }^{1}$
}

\section{RESUMEN}

El estudio de los sistemas de identificación personal de la nobleza permite conocer la evolución de su estructura interna, en un tiempo en el que se estaban dando los primeros desde el cognatismo hacia el agnatismo. Además, la antroponimia fue un mecanismo utilizado por la nobleza para construir su identidad y memoria familiar, mediante la repetición de determinadas costumbres onomásticas. En este artículo se analizarán los usos antroponímicos de la nobleza leonesa durante la segunda mitad del siglo XII y comienzos del siglo XIII, a través del análisis de tres parentelas nobiliarias: Flaínez, Cabrera y Traba.

Palabras clave: Antroponimia, nobleza leonesa, identidad y memoria nobiliaria, Flaínez, Cabrera, Traba.

\begin{abstract}
Research of personal identification systems among nobles allows to assess the evolution of their inner structure in a time when primogeniture was beginning to shift from a cognatic to an agnatic one. Personal names giving was an additional mechanism of which nobility made use in order to build their identity and family's memory through repetition of specific name-giving habits. In this paper naming habits of León nobility in the second half of the 12 th century and early 13th century will be examined by exploring three noble lineages Flaínez, Cabrera and Traba.
\end{abstract}

Keywords: Personal names, León nobility, nobility’s identity and memory, Flaínez, Cabrera, Traba.

Fecha de recepción: 1 de marzo de 2011. Fecha de aceptación: 4 de abril de 2011

1 Este trabajo forma parte del proyecto "La nobleza leonesa entre la expansión y la crisis (1230-1312)", financiado por el programa de ayudas de movilidad postdoctoral del Ministerio de Educación del Gobierno de España. CEPESE-Universidade do Porto. Email: inescalderon1@hotmail.com. 
La antroponimia medieval ha sido objeto de estudio desde mediados del siglo XIX, cuando eruditos como Godoy Alcántara comenzaron a estudiar la importancia de los apellidos $^{2}$. A principios del siglo XX la antroponimia comenzó a emplearse para el estudio de procesos migratorios ${ }^{3}$. En los últimos veinte años se ha destacado la importancia de este elemento para el conocimiento de la sociedad medieval y se han recogido los resultados más fructíferos ${ }^{4}$. En 1995 un amplio grupo de investigadores estudió los sistemas de identificación durante los siglos IX al XIII en los reinos cristianos ibéricos. A su juicio, el estudio de los sistemas de identificación constituye una herramienta de interés para analizar procesos como la cristianización, las migraciones, los grupos sociales y las estructuras de las familias 5 . Los integrantes de este equipo destacan que es necesario incluir numerosos matices y establecer estrechas acotaciones geográficas y temporales para obtener resultados específicos. Asimismo, señalan que hay que tener en cuenta la parcialidad y la naturaleza de las fuentes de las que se dispone, pues, al no conservarse documentación seriada, resulta complicado elaborar estudios estadísticos completos. Aunque estos trabajos se encuadran en marcos generales, son reveladores de la evolución de los sistemas de denominación personales a lo largo de la Edad Media ibérica.

El empeño de los investigadores ha revelado la importancia de la antroponimia como signo de diferenciación, ya que los distintos estamentos sociales incorporan pequeñas particularidades en sus modos de denominación. El análisis de la antroponimia en los estudios sobre la aristocracia medieval ha permitido conocer los entresijos de la estructuración interna de la familia y la evolución desde los sistemas de organización cognaticios hasta los agnaticios ${ }^{6}$. En estas páginas estudiaremos los sistemas utilizados por la aristocracia

2 Godoy Alcántara, J. Ensayo histórico, etimológico, filológico sobre los apellidos castellanos, Madrid 1871, ( ed. Facsímil Barcelona 1975).

3 A principios del siglo XX aparecieron dos trabajos clásicos que tomaron la antroponimia como principal instrumento para el estudio de la emigración y establecimiento de población mozárabe y franca en tierras castellanas durante la plena Edad Media, véase Gómez Moreno, M. Iglesias mozárabes. Arte español de los siglos IX al XI, Centro de Estudios Históricos, Madrid 1919 y Serrano, L. El obispado de Burgos y Castilla primitiva desde el siglo V al XIII, Impr. E. Maestre, Madrid, 1935.

4 Sobre la utilización de la antroponimia en el estudio de la Edad Media véase, MArTínez SoPENA, P. "Notas sobre la antroponimia hispánica medieval", Medievalismo, no 4, (1994), pp. 189-197.

5 Martínez Sopena, P. (coord.) Antroponimia y sociedad. Sistemas de identificación hispano-cristianos en los siglos IX a XIII, Universidad de Santiago de Compostela/ Universidad de Valladolid, Valladolid 1995, p. 11. El equipo investigador estaba integrado, entre otros, por J. A García de Cortázar, C. Laliena, J. I. Ruiz de la Peña, Ll. To Figueras, J. Montenegro Valentin, M. C Pallares, E. Portela, P. Martínez Sopena. En la última década el equipo investigador dirigido por Monique Bourain y Pascual Martínez Sopena ha utilizado la antroponimia como elemento para el estudio de las migraciones, véase BourAin. M. y MARTínez SoPEnA, P., Antroponymie et migration dans la Chétienté medieval, Casa de Velázquez, Madrid 2010.

6 Numerosos investigadores han reparado en la importancia de la antroponimia en este campo, como PORTELA, E; y Pallares, C. "Aristocracia y sistemas de parentesco en la Galicia de los siglos centrales de la Edad Media. El grupo de los Traba”, Hispania, no 185, 1993, pp. 823-844. MARTíneZ SoPENA, P. "El conde Rodrigo de León y los suyos. Herencia y expectativa del poder entre los siglos X y XII" en PASTOR DE TOGNERI, R., Relaciones de Poder, de producción y de parentesco en la Edad Media y Moderna: una aproximación a su estudio, CSIC, Madrid, 1990, pp. 51-84. Martínez SopenA, P., "La Parentesco y poder en León durante el siglo XI. La casata de Alfonso Díaz", Studia Historica, Historia Medieval V, (1987), pp. 33-87. Calleja PuerTa, M. El conde Suero Vermúdez, su parentela y su entorno. La aristocracia asturleonesa en los siglos XI y XII" KRK, Oviedo 2004. SALAZAR ACHA, J., "Una familia en la Alta Edad Media. Los Velas y su realidad histórica”: Estudios Genealógicos y Heráldicos, 1, 1985. SUÁrEZ, S. "Notas al sistema antroponímico asturiano de los siglos X al II" Asturiensia medievalia, 6, pp. 59-72. 
leonesa durante la segunda mitad del siglo XII y primer cuarto del siglo XIII. Adelantamos que es un periodo corto, en que no se aprecia una gran evolución en los modos de denominación personal, pero se observa la implantación del uso del antropónimo y patronímico entre los varones nobles y, en menor medida, entre las mujeres. Además se documentan nuevos comportamientos como el empleo de partículas toponímicas asociadas al nombre y la fosilización del apellido, avanzado el periodo.

Para llevar a cabo este estudio hemos creado un corpus documental facticio; es decir, hemos seleccionado los diplomas en los que participan los miembros de tres parentelas, pertenecientes a cuatro generaciones entre 1157 y 12307. Estas parentelas son los Traba gallegos, los Flaínez leoneses y los descendientes de Ponce de Cabrera. Se trata de ciento cincuenta y cinco personas: noventa y cinco hombres y sesenta mujeres. Los historiadores que nos han precedido han estudiado los sistemas de denominación de alguna de estas familias, mientras que otras no han sido objeto de este tipo de estudios, por lo que intentaremos recoger los resultados de sus trabajos y añadir las conclusiones que podamos extraer de la evolución de los modos de denominación personales de la nobleza leonesa y el uso que hicieron de ellos como elementos de creación de la identidad y memoria de la familia.

\section{A. LOS SISTEMAS DE IDENTIFICACIÓN DE LA NOBLEZA LEONESA}

Tras un lento avance desde el siglo X, en la duodécima centuria se implantó de manera generalizada en el estamento nobiliar el empleo de dos elementos como sistema de denominación personal ${ }^{8}$. El nombre de dos elementos estaba integrado por un nombre de pila al que se añadía el nomen paternum ${ }^{9}$, que variaba a cada generación puesto que aún no había cristalizado en el apellido, lo que ocurrió cuando se establecieron las estructuras agnáticas en los siglos posteriores; no obstante, la reiteración de nombres y patronímicos en el seno de una parentela generaba una clara conciencia de grupo, además de constituir un recuerdo de los antecesores. Este sistema de denominación fue mayoritariamente utilizado por los varones y, en menor grado, por las féminas que habitualmente se denominaban sólo el nombre de pila. Pero cuando un individuo podía ser reconocido fácilmente por su nombre de pila y dignidad, solía obviar su patronímico. Esta circunstancia se registra sobre todo entre los grandes dignatarios de la corte.

Si bien el nombre de dos elementos fue mayoritario, en torno a 1160 determinados individuos comienzaron a introducir un tercer elemento toponímico asociado al lugar

7 En los casos en los que hemos logrado reconstruir a la quinta generación, la hemos incluido como objeto de estudio.

8 Torres Sevilla, M. Antroponimia nobiliaria leonesa durante el siglo X. Las casas de Cea y Saldaña. Vida Cotidiana en la España Medieval, en Aguilera Castro, M $^{\mathrm{a}}$ C. Actas del VI Curso de Cultura Medieval, celebrado en Aguilar de Campoo del 26 al 30 de septiembre de 1994, pp. 231-244.

9 Martínez Sopena tras analizar el fondo de la catedral de León estima que en 1200 el $80 \%$ de los varones que aparecen en la documentación lo hacen con dos elementos, mientras que sólo el 17\% utiliza el nombre de pila exclusivamente. Martínez Sopena, P. "La antroponimia leonesa. Un estudio del Archivo de la Catedral de León (876-1200), en Martínez SopenA, P. Antroponimia y sociedad. Sistemas de identificación hispano-cristianos en los siglos IX a XIII, Universidad de Santiago/Universidad de Valladolid, Valladolid 1995, pp. 155-180. Ésta es una situación que puede apreciarse en otras regiones del antiguo reino de León como Asturias y Galicia. 
donde ejercían su poder. Este toponímico se convierte en un cognomen personal, que individualiza a un determinado individuo y no a su parentela, al menos, esto parece suceder entre los Traba y los $\operatorname{Lara}^{10}$, así como en otros de los casos que estudiaremos a continuación. Fueron varios los miembros de cada una de las parentelas los que emplearon estos topónimos como distintivo que posteriormente se convertirían en el apellido familiar a medida que se fueron implantando en la sociedad las estructuras agnáticas ${ }^{11}$.

\section{a) Los nombres de pila}

En el estamento nobiliar la elección de los nombres de pila refleja una clara conciencia familiar, puesto que se repiten en las sucesivas generaciones de la misma familia. Habitualmente estos nombres configuran un reducido stock que va aumentando con cada alianza matrimonial, porque se introducen los nombres de la parentela con la que se ha establecido un nuevo vínculo.

Los nombres de pila más frecuentes entre los varones de la familia Flaínez son "Diego", "Froila" y "Ramiro" que se repiten cada dos generaciones. Diego Pétriz era el padre de Froila Díaz. Éste, siguiendo las pautas habituales, denominó a su primogénito varón "Diego", como su progenitor, y uno de sus nietos, Diego Froilaz II, recibiría el mismo nombre. "Froila" se introdujo en la familia por vía femenina en el siglo XI, ya que el padre de la primera María Froilaz era el conde Froila Muñoz. Así, se denominarán los miembros de la familia en sucesivas generaciones, como Froila Díaz y el primogénito de Ramiro Froilaz, don Froila Ramírez, que recibió el nombre en honor a su abuelo paterno.

También por vía femenina se introdujo el nombre de Ramiro, que era característico de la familia real navarra de la que procedía doña Estefanía Sánchez, esposa de Froila Díaz. El primer miembro de la familia en llevar este nombre de pila fue su hijo, el conde Ramiro Froilaz, y posteriormente los nietos primogénitos varones de éste, Ramiro Froilaz II y Ramiro Ponce (de Minerva). Asimismo, García es otro de los nombres con clara ascendencia navarra que se incorporó a la parentela por la misma línea femenina.

En la tercera generación aparece un nuevo nombre en la familia: Nuño. Se trata de Nuño Menéndez, hijo de María Froilaz y Melendo Núñez, que recibió el nombre de su abuelo paterno.

En la cuarta generación se aprecia un aumento en el stock de nombres de pila, puesto que se introducen los característicos de la familia Traba con la que emparentaron los Flaínez a través del matrimonio entre Froila Ramírez y Sancha Fernández de Traba. Así, sus hijos se llamarán Vermudo y Rodrigo como el abuelo y tío de doña Sancha, Vermudo y Rodrigo Pérez de Traba.

10 Véase Portela, E. y Pallares, C. “Aristocracia y sistemas de parentesco en la Galicia de los siglos centrales de la Edad Media. El grupo de los Traba” Hispania LIII/3 n 185 (1993), p. 823-840. SÁnCHEZ DE MoRA, A. Los Lara. Un linaje castellano en la Plena Edad Media, Diputación Provincial de Burgos, Burgos 2007, p. 157.

11 PARdo DE Guevara y VAldÉs, E. "Identidad y memoria genealógica. Una aportación al estudio de la antroponimia medieval gallega", Anuario de estudios medievales, 39/1, (2009), pp. 27-45. 
NOMBRES DE PILA DE LA FAMILIA FlAÍNEZ

\begin{tabular}{|c|c|c|c|c|}
\hline Nombre & $\mathbf{1}^{\mathbf{a}}$ generación & $\mathbf{2}^{\mathbf{a}}$ generación & $\mathbf{3}^{\mathbf{a}}$ generación & $\mathbf{4}^{\mathbf{a}}$ generación \\
\hline Froila & 1 & & 1 & \\
\hline Ramiro & & 1 & & 2 \\
\hline Diego & & 1 & & 1 \\
\hline Alfonso & & & 1 & 1 \\
\hline García & & & & 1 \\
\hline Vermudo & & & & 1 \\
\hline Rodrigo & & & & \\
\hline Nuño & & & & \\
\hline
\end{tabular}

22 individuos = 12 hombres y 10 mujeres. Descendencia de Froila Díaz y Estefanía Sánchez.

Entre las mujeres el stock onomástico es aún más reducido. Predomina el nombre María, si bien, se generalizó en los siglos medievales es un indicador de los usos familiares. Así se llamaba la esposa de Diego Pétriz, doña María Froilaz e igual nombre recibió su nieta María Froilaz (II). Dos de sus bisnietas también lo portarían (María Pérez y María Ponce).

\begin{tabular}{|c|c|c|c|c|}
\hline Nombre & $\mathbf{1}^{\text {a }}$ generación & $\mathbf{2}^{\text {a }}$ generación & $\mathbf{3}^{\text {a }}$ generación & $\mathbf{4}^{\text {a }}$ generación \\
\hline María & & 1 & 1 & 1 \\
\hline Estefanía & 1 & & 2 & 1 \\
\hline Teresa & & & & 1 \\
\hline Inés & & & & 1 \\
\hline Sancha & & & & \\
\hline Mayor & & & 1 & \\
\hline
\end{tabular}

Estefanía Sánchez era la esposa de Froila Díaz, que aportó sangre real a la parentela. Quizá como homenaje a tan insigne dama, dos de sus nietas, las hijas de sus hijos Diego y Ramiro, recibirían el mismo nombre. La hija de Alfonso Ramírez recibiría de igual modo el nombre de su abuela paterna, doña Inés, del linaje de los reyes de Francia. En la cuarta generación se incorpora el nombre de Teresa, asociado con la familia Traba, que se introdujo en la familia a raíz de la unión entre el conde Froila Ramírez y doña Sancha. 


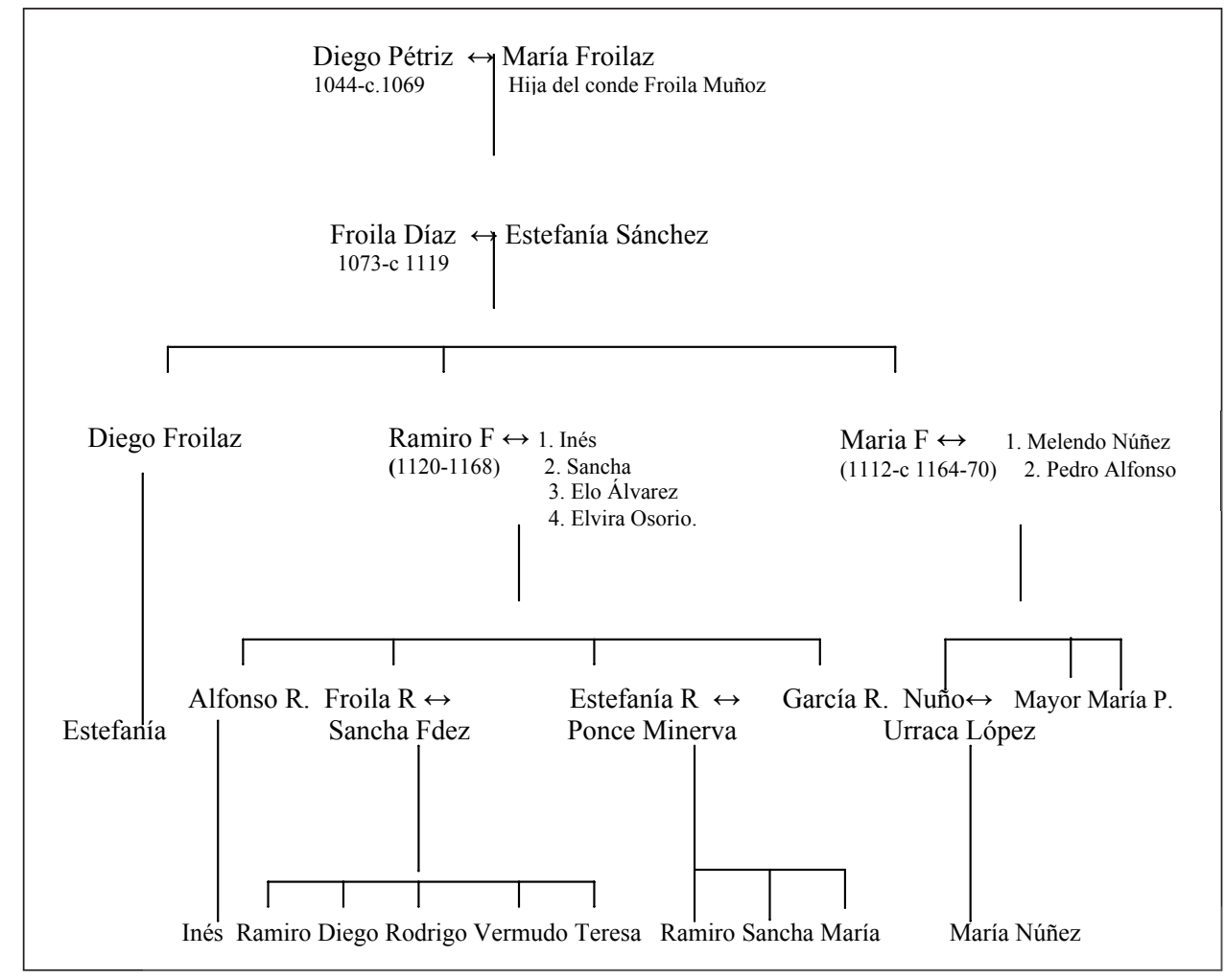

La segunda parentela objeto de nuestro análisis es la de Ponce de Cabrera. El motivo de esta elección reside en la condición de extranjero del magnate, que se estableció en el reino leonés a partir de 1129, procedente de tierras catalanas, donde el sistema de denominación personal seguía otras normas bien establecidas y diferentes a la costumbre leonesa ${ }^{12}$. Por ello, es interesante observar cómo este magnate, que emparenta con familias leonesas, adopta los sistemas de denominación personal vigentes en León, abandonando los usos catalanes. Posteriormente, su descendencia obedecería la tradición leonesa, aunque conservó elementos que dejan vislumbrar el origen lejano de su familia.

Ponce de Cabrera introdujo consigo una onomástica propia de los reinos orientales que, a partir de entonces, comenzaría a mezclarse tímidamente con la onomástica de las tradicionales familias nobiliarias de León. Transmitiría a su descendencia algunos nombres de pila propios de su familia, como Giraldo o Ponce. Su primogénito se llamó Giraldo, igual que su abuelo paterno; pero este nombre no volvería a ser utilizado por sus descendientes, a pesar de que se trataba de uno de los nombres de linaje más difundido en

12 To Figueras, L1. “Antroponimia de los condados catalanes”, en Martínez Sopena, P. (coord.), Antroponimia y sociedad. Sistemas de identificación hispano-cristianos en los siglos IX a XIII, Universidad de Santiago/ Universidad de Valladolid. Valladolid 1995, pp. 371-394. 
la rama catalana de la familia hasta aquel momento. Pero no ocurrió lo mismo con Ponce. Este nombre de pila continuó siendo transmitido hasta la tercera generación. No obstante, parece que dejó de ser utilizado en las sucesivas generaciones como nombre de pila o, al menos, no ha quedado constancia documental de ello ${ }^{13}$.

Fernando es otro de los nombres habituales en la familia; probablemente llegó por línea femenina a través de doña Sancha, la primera esposa del conde Ponce de la que se desconoce su filiación. Pero ese mismo nombre llegó a la familia también por otro cauce: nuevamente por la línea femenina representada por la segunda esposa del conde, doña María Fernández de Traba, que llamó a su hijo con el nombre de su abuelo, Fernando. Estas circunstancias provocaron que Ponce de Cabrera tuviera dos hijos homónimos, por lo que para distinguirlos fue necesario añadirles un cognomento: el mayor y el menor. Fernando fue transmitido a la tercera generación a través de Fernando Ponce y por vía femenina, Sancha Ponce, que llamó de esta manera a su hijo. En la cuarta generación vuelve a aparecer un Fernando y el nombre pervivirá entre la familia al menos hasta la quinta generación. No obstante, hay que destacar que la cadena de transmisión de este nombre fue a través de la descendencia de la primera esposa de Ponce de Cabrera, ya que no hay constancia documental de que perviviera el nombre de Fernando en la descendencia de María Fernández de Traba.

En la tercera generación se incorporan nombres de devociones privadas como Pedro y Juan, además de García y Rodrigo, aportados por línea masculina gracias al matrimonio de Vela Gutiérrez con Sancha Ponce ${ }^{14}$. En la cuarta generación se incrementa el uso de Juan, quizá en recuerdo a Juan Vela, fallecido antes de 1181, sus hermanos, Fernando y Ponce Vela, pusieron tal nombre de pila a sus hijos, Juan Fernández y Juan Ponce.

En este caso hemos logrado reconstruir una parte importante de la quinta generación de la familia ${ }^{15}$, en la que aparecen de nuevo nombres recurrentes, como Fernando, Pedro y Juan, además de otros con un claro origen portugués, como Ruy (por influencia del matrimonio entre Pedro Ponce y la hija bastarda de Alfonso IX, doña Aldonza Alfonso, nacida de su relación con la dama lusitana Aldonça Martins da Silva)

13 Hay que recordar que probablemente no se han conservado noticias de todos los miembros de la familia y que es factible que algún integrante de la siguiente generación pudiera haberse llamado Ponce y que falleciera antes de alcanzar la edad adulta.

14 Vela Gutiérrez era hijo de Gutierre Vermúdez y Toda Pérez de Traba. En ambas familias era habitual el nombre de Rodrigo, por lo que no se puede discernir por qué vía se introdujo. García probablemente se adoptó como nombre de la familia de Vela Gutiérrez a través de su abuela materna doña Mayor Gontroda, ya que uno de sus hijos habidos con Pedro Froila de Traba y, por tanto, tío de Vela, llevaba ese nombre.

15 Afortunadamente se puede reconstruir gran parte de esta parentela hasta el siglo XV, pero aunque hemos seleccionado las cinco generaciones siguientes a Ponce de Cabrera para estudiar los usos antroponímicos, hemos añadido en el cuadro genealógico algunos individuos de las siguientes generaciones porque permiten conocer la interesante evolución antroponímica que sufrió esta parentela. 
Nombres de PIla familia Ponce DE CABRera

\begin{tabular}{|c|c|c|c|c|c|}
\hline Nombre & $\mathbf{1}^{\mathbf{a}}$ Generación & $\mathbf{2}^{\mathbf{a}}$ Generación & $\mathbf{3}^{\text {a }}$ Generación & $\mathbf{4}^{\mathbf{a}}$ Generación & $\mathbf{5}^{\mathbf{a}}$ Generación \\
\hline Ponce & 1 & & 1 & & \\
\hline Giraldo & & 1 & & & \\
\hline Fernando & & 2 & 2 & 1 & 1 \\
\hline Rodrigo & & & 1 & & 1 \\
\hline García & & & 1 & & 1 \\
\hline Juan & & & 1 & 2 & 1 \\
\hline Pedro & & & 2 & 1 & 1 \\
\hline Ruy & & & & & \\
\hline
\end{tabular}

\begin{tabular}{|c|c|c|c|c|c|}
\hline Nombre & $\mathbf{1}^{\text {a }}$ Generación & $\mathbf{2}^{\text {a }}$ Generación & $\mathbf{3}^{\text {a }}$ Generación & $\mathbf{4}^{\text {a }}$ Generación & $\mathbf{5}^{\text {a }}$ Generación \\
\hline Sancha & 1 & 1 & & & \\
\hline María & 1 & & 1 & & \\
\hline Juana & & & & & 1 \\
\hline Elvira & & & & & 1 \\
\hline
\end{tabular}

El stock de nombres de pila femenino era sustancialmente menor. Se repiten Sancha entre madre e hija y María; no obstante, las dos mujeres que comparten este nombre no eran consanguíneas porque María Fernández de Traba no era la madre de Sancha Ponce y, por tanto, no era abuela de María Vélaz. Esta circunstancia puede explicarse por la difusión del nombre María, muy habitual entre las féminas.

Como tercer ejemplo hemos seleccionado a los Traba gallegos. Se conservan referencias de más de cien de sus miembros, lo que constituye una muestra suficientemente extensa y reveladora de los sistemas de identificación personal utilizados por la nobleza. 


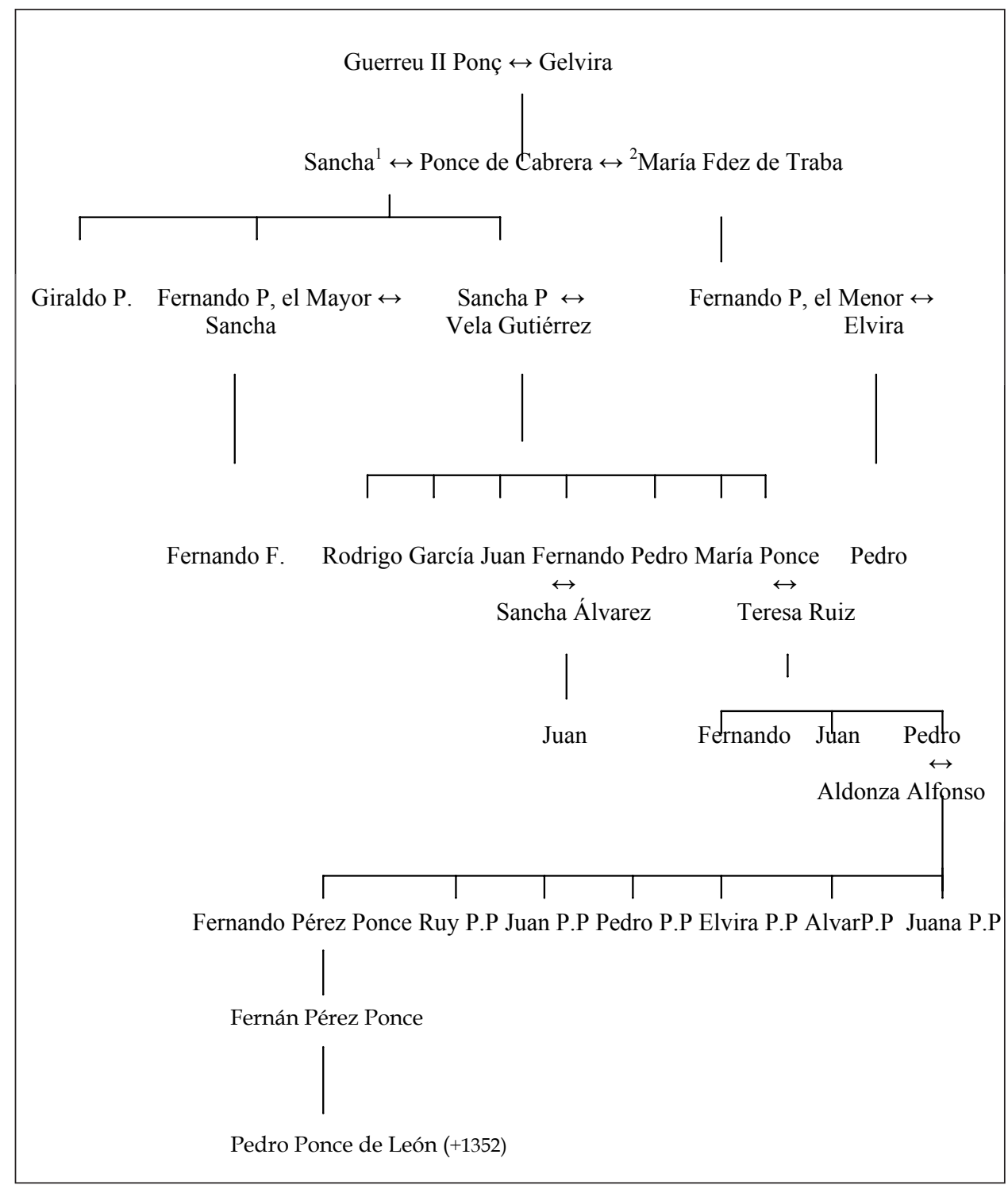


NOMBRES DE PILA FAMILIA CABRERA

\begin{tabular}{|c|c|c|c|c|c|}
\hline Nombre & $1^{a}$ Generación & $2^{\mathrm{a}}$ Generación & $3^{\text {a Generación }}$ & $4^{\mathrm{a}}$ Generación & $5^{a}$ Generación \\
\hline Pedro & 1 & & 2 & 1 & 2 \\
\hline Vermudo & & 1 & & 1 & 1 \\
\hline Fernando & & 1 & 2 & 6 & 4 \\
\hline Rodrigo & & 1 & & 3 & \\
\hline Froila & & 1 & & 1 & \\
\hline García & & 1 & & 1 & \\
\hline Velasco & & 1 & & 1 & \\
\hline Juan & & & & 1 & \\
\hline Enrique & & & 1 & 1 & \\
\hline Sancho & & & & 1 & \\
\hline Gonzalo & & & 1 & 1 & 1 \\
\hline Gómez & & & & 1 & 1 \\
\hline Álvaro & & & & 2 & \\
\hline Nuño & & & & 1 & \\
\hline Vela & & & & 1 & \\
\hline Suero & & & 1 & & \\
\hline Bernardo & & & 1 & & \\
\hline Manrique & & & 1 & & \\
\hline Gutierre & & & 1 & & \\
\hline Egidio & & & & 1 & \\
\hline Martín & & & & 1 & \\
\hline Munio & & & & 1 & \\
\hline Osorio & & & & 1 & \\
\hline Fortún & & & & 1 & \\
\hline Ruy & & & & 1 & \\
\hline Lorenzo & & & & 2 & \\
\hline Ponce & & & & 2 & \\
\hline Juan & & & & & 1 \\
\hline Ramiro & & & & & 1 \\
\hline Diego & & & & & 1 \\
\hline
\end{tabular}


Partiendo del magnate Pedro Froilaz de Traba y extendiéndonos hasta la quinta generación, hemos registrado un total de ciento siete individuos de los que sesenta y tres son hombres, y cuarenta y cuatro mujeres.

El árbol genealógico de esta parentela tiene numerosas ramificaciones que aportan un amplio número de nombres de pila al stock familiar, gracias a las alianzas con otras familias. Estos nombres se integrarán en la familia y se transmitirán en las siguientes generaciones ${ }^{16}$.

Entre los nombres de linaje más antiguos se registra Froila desde siete generaciones anteriores a Froila Pérez ${ }^{17}$, hijo primogénito de Pedro Froilaz. Este nombre se había introducido por varias vías; así los dos abuelos de Froila Pérez eran homónimos y por ello quizá el hijo de Pedro Froilaz recibió tal nombre. No obstante, y a pesar de la gran tradición de Froila en la familia, el nombre no tuvo una gran proyección en las generaciones posteriores. Tal vez se extinguió porque Froila Pérez murió sin descendencia. Resulta extraño que un nombre de tan honda raigambre en la parentela se perdiera sin dejar rastro en las siguientes generaciones, lo que induce a pensar que probablemente otros varones con el mismo nombre murieron antes de alcanzar la edad adulta.

DESCENDENCIA PRIMER MATRIMONIO PEDRO FROILAZ

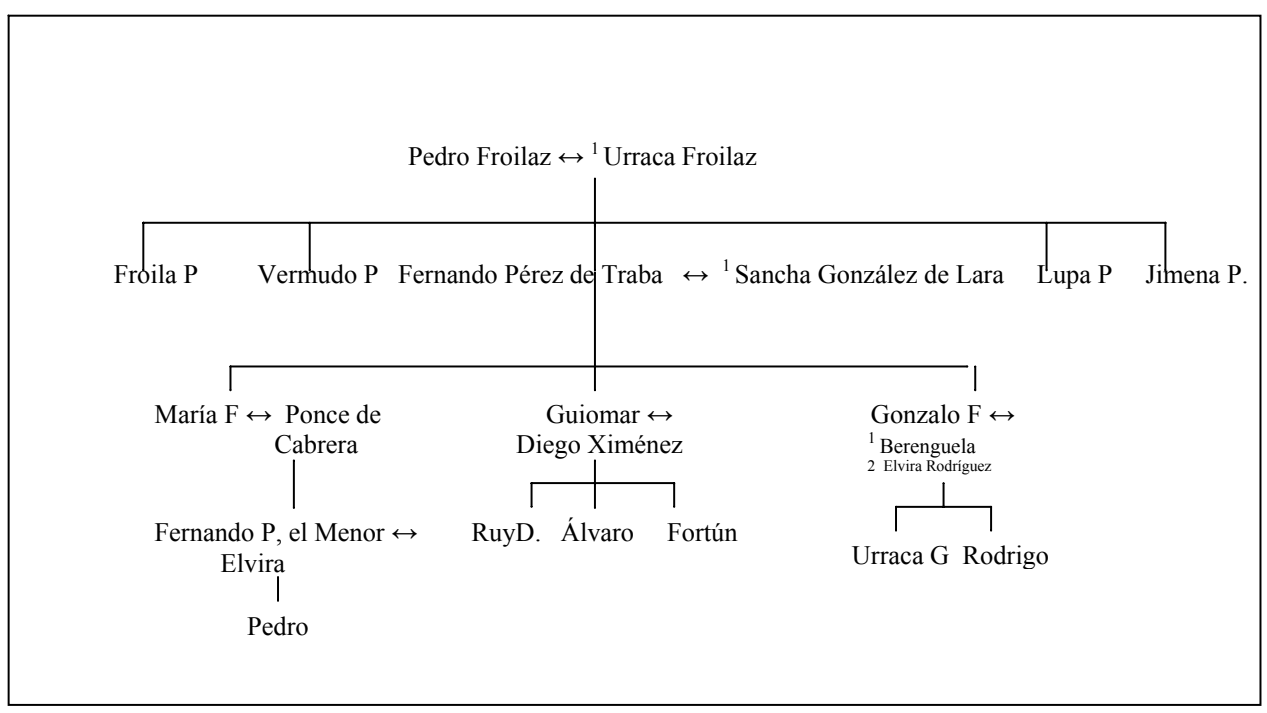

16 Esta multitud de ramas colaterales aporta una gran riqueza a la muestra seleccionada al tiempo que incorpora un amplio grado de dificultad a su estudio porque, en ocasiones, parece desdibujar el esquema seguido por los integrantes de la parentela en cuanto a los sistemas de identificación personal.

17 Seguimos en esta aseveración a López San Gil que a pesar de que destaca los oscuros orígenes de la familia, estima fiable la genealogía que en 1779 trazó Mauricio Carbajo en Cronicón de Santa María de Sobrado. Manuscrito. Biblioteca Universidad de Santiago. En esta reconstrucción genealógica de los descendientes de Gutierre Aloitez se puede observar que desde siete generaciones anteriores, Froila es uno de los nombres más frecuentes en la familia. LóPEZ SAN GIL, J.L. La nobleza altomedieval gallega. La familia Froilaz -Traba, Toxosoutos, Noia 2002, pp. 13 y 239. 
DESCENDENCIA FERNANDo PÉREZ de Traba

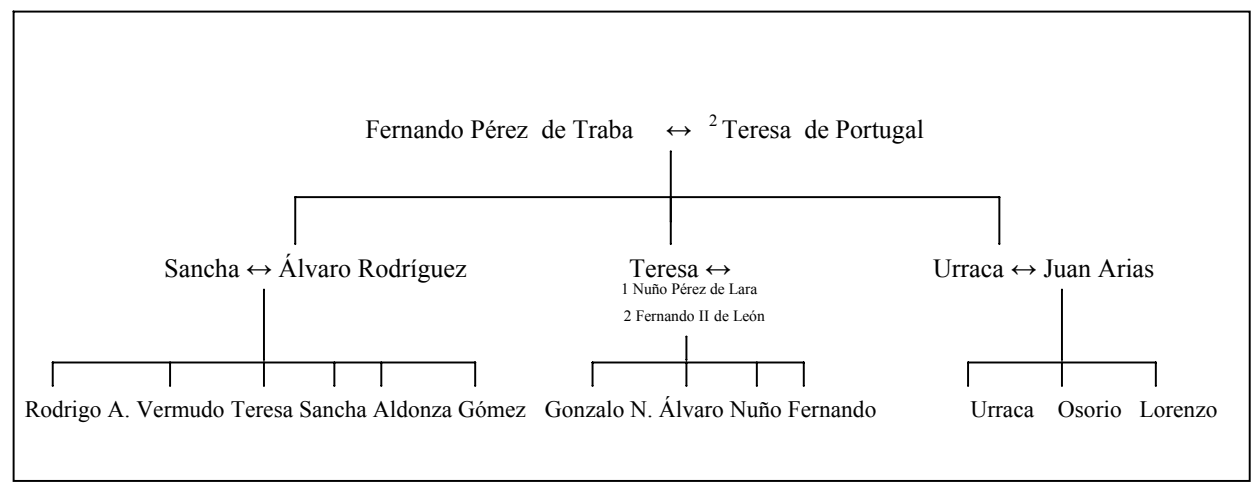

DESCENDENCIA LUPA PËREZ DE TRABA

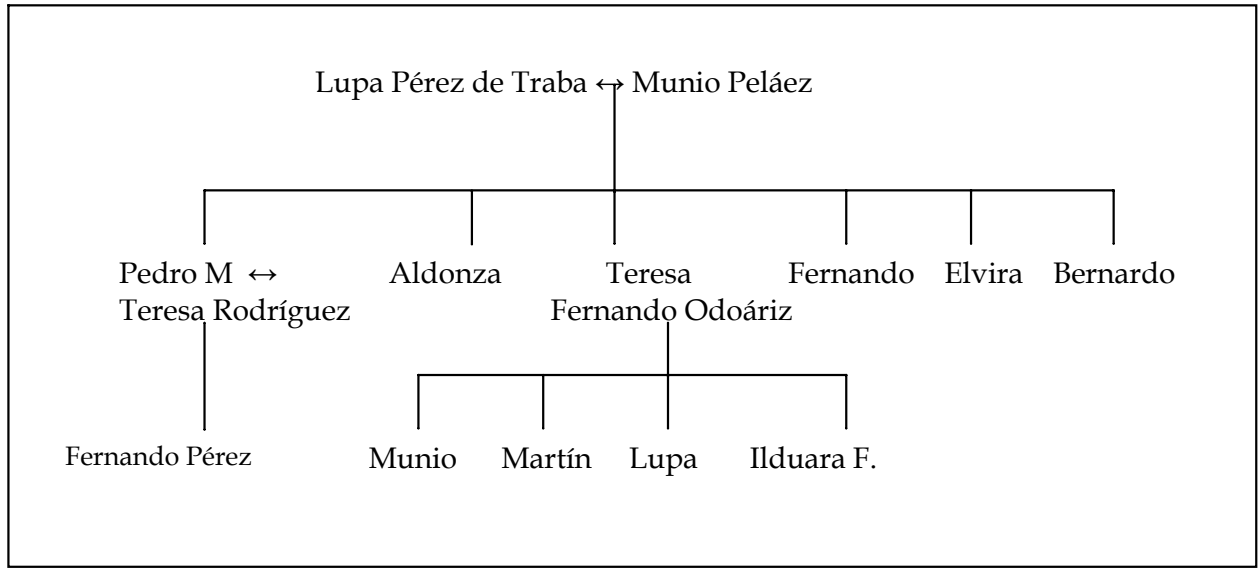

Pedro es otro de los nombres de pila que se transmitirá sucesivamente en la familia. Aparte de don Pedro Froilaz, dos de sus nietos llevarían el mismo nombre. Se trata de Pedro Muñoz, hijo de Lupa Pérez, y Pedro Vermúdez, el primogénito del primer matrimonio de Vermudo Pérez. En la cuarta generación se registra otro Pedro, hijo de Vela Gutiérrez, que recibió el nombre a través de la línea de su abuela paterna, doña Toda Pérez de Traba. En la quinta generación aparece Pedro Ponce, sobrino del anterior. 

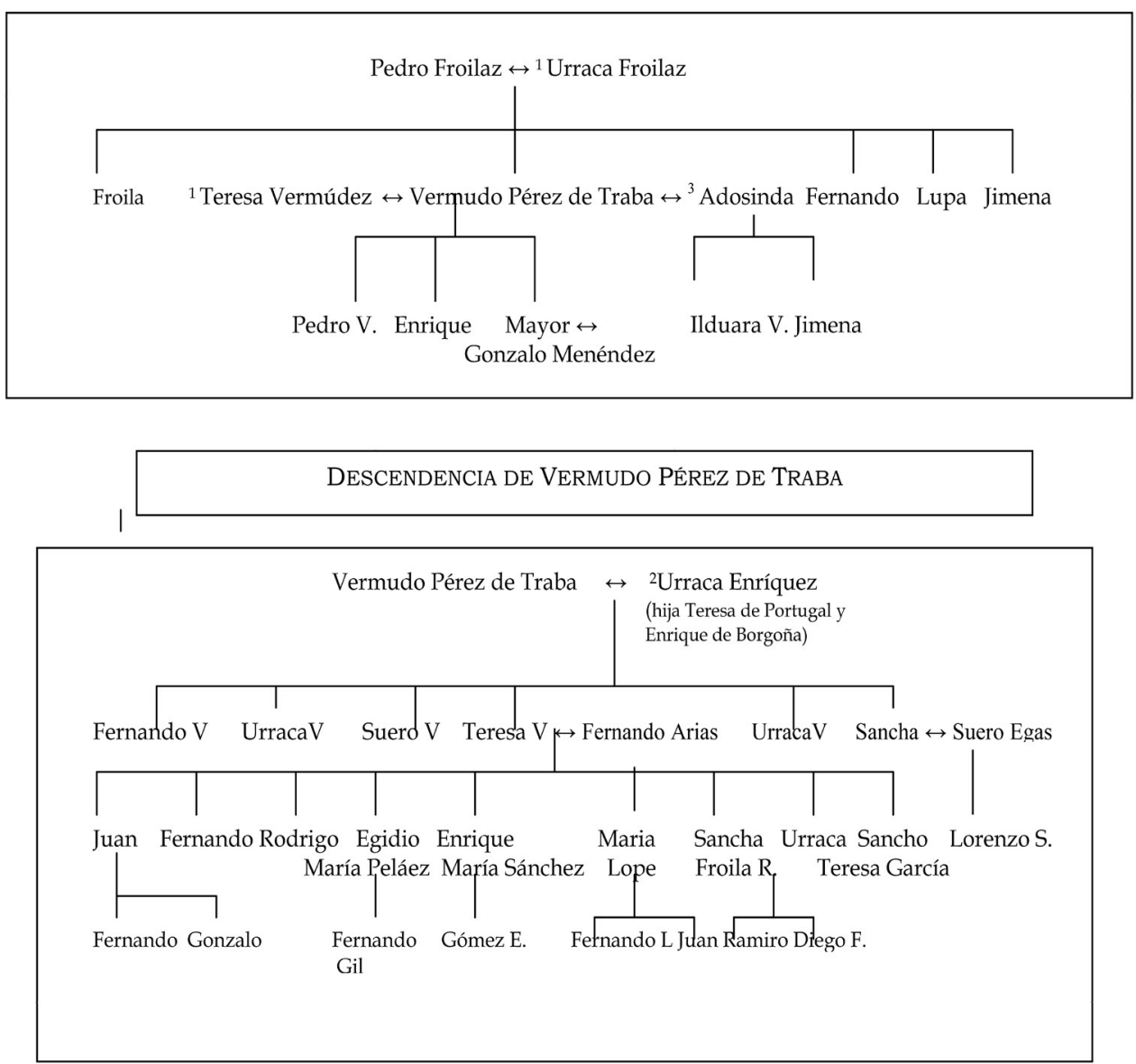

Pero sin duda, Fernando será el nombre de pila que mayor proyección alcance en la familia. En las cinco generaciones seleccionadas se registran catorce individuos con ese nombre, lo que representa un $20 \%$ de los varones de la familia. No obstante, es preciso destacar que a lo largo de las cinco generaciones, el mismo nombre de pila se introdujo por varias vías, tras los enlaces de Teresa Vermúdez con Fernando Arias y el de Estefanía Pérez con Rodrigo Fernández de Castro, lo que propició la multiplicación del empleo de este nombre. Así, además de Fernando Pérez de Traba llevarán el mismo nombre sus sobrinos Fernando Vermúdez, primogénito de Vermudo Pérez y su segunda esposa, doña Urraca, y Fernando Muñoz, hijo de Lupa Pérez. Es en la cuarta generación cuando se aprecia el incremento de este nombre, pues se registran seis Fernandos: Fernando Fernández, hijo de Teresa Vermúdez y Fernando Arias, Fernando Ponce, hijo de María Fernández de 
Traba y Ponce de Cabrera; su primo Fernando Núñez, hijo de Teresa Fernández y Nuño Pérez de Lara, Fernando Pérez, nieto de Lupa Pérez; Fernando Rodríguez de Castro, nieto de Estefanía Pérez de Traba y Rodrigo Fernández de Castro, y Fernando Vela, nieto de Toda Pérez y Gutierre Vermúdez. En la siguiente generación, la quinta, sólo hemos podido reconstruir algunas ramificaciones, aunque se constata la pervivencia de este nombre de pila que llevan tres bisnietos de Vermudo Pérez de Traba y uno de Toda Pérez.

"Vermudo" se introdujo en la familia en el siglo XI y se transmitió al menos hasta comienzos del siglo XII, a lo largo de siete generaciones ${ }^{18}$. En la muestra seleccionada el primero en llevar ese nombre sería Vermudo Pérez de Traba, hijo de Pedro Froilaz y, posteriormente, habrá que esperar a la cuarta generación para documentar a otro individuo con ese nombre: Vermudo Álvarez a quien llegó el nombre por vía materna, ya que era hijo de Sancha Fernández de Traba y Álvaro Rodríguez de Sarria. En la generación posterior, y de nuevo por vía femenina, se registra a Vermudo Froilaz, hijo de Sancha Fernández (hija de Teresa Vermúdez y Fernando Arias) y Froila Ramírez.

Éstos son los principales nombres, aunque si se observa el cuadro se aprecia un gran incremento en el stock onomástico en la cuarta generación, motivado por la introducción de otros nombres característicos de otras familias que emparentaron con los Traba. Así, se registran nombres como Fortún, proveniente del linaje de los Cameros, representado por Diego Jiménez, u otros propios de los Lara, como Álvaro, Gonzalo, Manrique, Nuño. Ponce; de los Ponce de Cabrera; Vela, de los Vermúdez asturianos o Ramiro, de los Flaínez leoneses, etcétera.

\begin{tabular}{|c|c|c|c|c|}
\hline Nombre & $\mathbf{1}^{\mathbf{a}}$ Generación & $\mathbf{2}^{\mathbf{a}}$ Generación & $\mathbf{3}^{\text {a }}$ Generación & $\mathbf{4}^{\mathbf{a}}$ Generación \\
\hline Toda & & 1 & & 1 \\
\hline Mayor & 1 & & 1 & 3 \\
\hline Estefanía & & 1 & 3 & 1 \\
\hline Urraca & 1 & 2 & 3 & 2 \\
\hline Teresa & & 1 & 2 & 2 \\
\hline Sancha & & 1 & 1 & 1 \\
\hline Elvira & & 1 & 1 & 1 \\
\hline María & & & 2 & 1 \\
\hline Guiomar & & 1 & 1 & 1 \\
\hline Aldonza & & 1 & 1 & \\
\hline Lupa & & 1 & 1 & \\
\hline Aldara & & 1 & & \\
\hline Jimena & & & & \\
\hline Eva & & & & \\
\hline
\end{tabular}

18 Siguiendo la genealogía de Carbajo, el primer Vermudo de la familia fue Vermudo Froilaz, padre de Froila Vermúdez y abuelo de Pedro Froilaz. 
Entre las mujeres de la familia los nombres que se repiten con mayor asiduidad son Urraca, Teresa, Sancha y Lupa. Urraca se introdujo en la familia a través de Urraca Froilaz, primera esposa de Pedro Froilaz. Sus nietas, las hijas de Vermudo y Fernando Pérez, recibieron el mismo nombre, incluso dos de las hijas de Vermudo Pérez se llamaban Urraca $^{19}$. Entre las hijas de Pedro Froilaz se registra una Urraca, nacida de su segundo matrimonio con doña Mayor. En la cuarta generación se registran tres Urracas en la rama de Urraca Froilaz: dos nietas de Fernando Pérez y una de Vermudo Pérez. Teresa entró a formar parte del stock familiar a través de doña Teresa de Portugal, amante de Fernando Pérez de Traba, y madre de Urraca, la segunda esposa de Vermudo Pérez. Así se llamó una de las hijas que tuvo con Fernando Pérez de Traba, que años más tarde se convertiría en reina de León. En la cuarta generación la hija de Sancha Fernández y Álvaro Rodríguez de Sarria se llamaría Teresa como su abuela materna, Teresa de Portugal y su tía, Teresa Fernández, la reina de León.

DESCENDENCIA SEgUNDO MATRIMONIO PEDRO FROILAZ

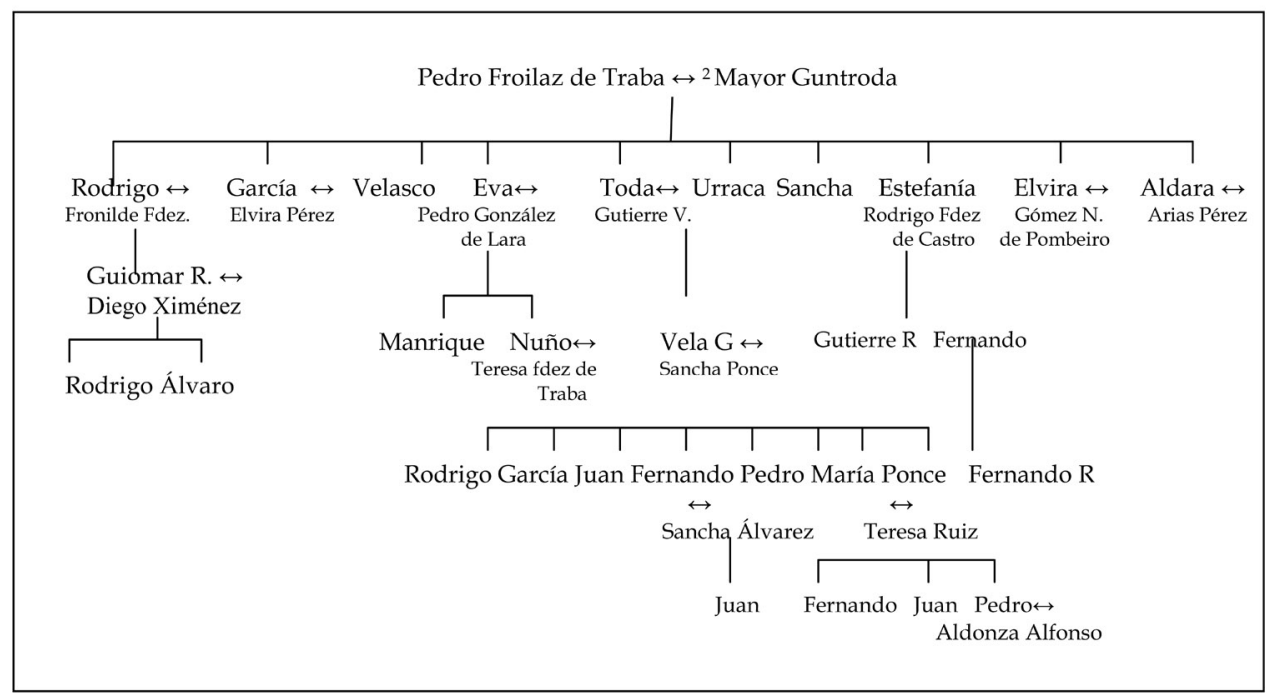

Lupa es uno de los nombres femeninos con mayor raigambre en la familia, aunque en las generaciones seleccionadas sólo documentamos a dos mujeres con este nombre. A pesar de ello, la línea de transmisión es clara: Lupa Pérez recibió el nombre en recuerdo a su bisabuela paterna Lupa Rodríguez-madre de Froila Vermúdez y abuela de Pedro

19 López San Gil afirma que ambas Urracas eran hijas de Vermudo Pérez y la portuguesa Urraca Enríquez, sin embargo, sospechamos que probablemente eran hijas de dos mujeres diferentes porque extraño que los hijos del mismo matrimonio recibieran el mismo nombre. Si bien es cierto que en el panorama nobiliario leonés se registran varios casos en los que los hijos de un magnate fueron homónimos, sin embargo eran hijos de distinta madre. Posteriormente nos ocuparemos de este aspecto. 
Froilaz $^{20}$; y su nieta Lupa Fernández, sería el siguiente eslabón de la cadena de transmisión de este nombre

Se desconoce la vía por la que el nombre Sancha se introdujo en la parentela, ya que la primera Sancha registrada es Sancha Pérez, la hija de Pedro Froilaz y su segunda esposa, doña Mayor; sospechamos que pudo ser por la vía de Pedro Froilaz, ya que dos de sus nietas, hijas de Fernando Pérez y Vermudo Pérez, recibieron el mismo nombre. Asimismo, el nombre pervivió en la siguiente generación, pues Sancha Fernández denominaría así a una de sus hijas.

Otros nombres como Aldara/ Ilduara, que se registra en la parentela desde cinco generaciones anteriores a las seleccionadas, tuvieron una gran continuidad pues se documenta en tres de las cuatro generaciones seleccionadas.

En el caso de las mujeres la incorporación de nuevos nombres al stock familiar es mucho menor de lo que sucedía con los hombres. Esta circunstancia puede estar motivada por una mayor preponderancia de la línea femenina en la transmisión de los nombres de las mujeres Traba, y una menor incorporación de nombres femeninos a través de alianzas con parentelas afines. Si bien es cierto que el número de féminas documentadas es inferior al de los varones, lo que podría distorsionar la estadística.

Aunque se aprecian ciertas diferencias entre los casos de las tres parentelas estudiadas, existen también algunas analogías que permiten extraer conclusiones generales acerca de los sistemas de identificación utilizados por la nobleza, a pesar de que se trata de parentelas asentadas en diversas zonas geográficas del reino.

En cuanto a la transmisión onomástica, en las tres parentelas estudiadas se aprecia una clara continuidad, al tiempo que resulta complicado descubrir cuáles eran las reglas de esta transmisión de los nombres de pila. Generalmente el primogénito varón portaba el mismo nombre de pila que su abuelo paterno ${ }^{21}$, el siguiente hijo varón solía tener el nombre del abuelo materno. Lo mismo sucedía con las hijas que eran denominadas como sus abuelas paterna y materna, respectivamente. El resto de los hermanos recibían otros nombres habituales en la parentela, y que coincidían habitualmente con los de sus tíos y tías, u otros parientes.

Estas formas antroponímicas traslucen la pervivencia de estructuras cognaticias pues a la descendencia se le daban los nombres de pila de las dos líneas de ascendencia, tanto la paterna como la materna.

\section{b) Nombre de pila+ nomen paternum}

Al nombre de pila se añade el nomen paternum, lo que provoca la repetición del mismo antropónimo y patronímico cada dos generaciones. Esto, unido a la repetición sistemática del stock de nombres familiares, genera una fuerte conciencia identitaria de

20 Según la genealogía de Carbajo que venimos utilizando.

21 De las tres parentelas seleccionadas el caso en el que mejor se aprecia este comportamiento es en el de la familia Flaínez. En varias ramas de la familia, el primogénito portaba el nombre de su abuelo paterno, como se aprecia en los ejemplos: Diego Pétriz-Froila Díaz-Diego Froilaz; Froila Díaz-Ramiro Froilaz-Froila RamírezRamiro Froilaz II. 
pertenencia a la parentela. Como destacaba Régine Hennebicque, el nombre era un elemento más de la herencia nobiliaria ${ }^{22}$.

El patronímico se añadía para destacar la filiación. En el estamento nobiliar más del 90\% de los hombres estudiados utilizan como sistema de denominación el antropónimo y el patronímico; aunque si se observan las listas de confirmantes de numerosos diplomas regios, se puede observar que los grandes magnates signan habitualmente sólo con el nombre de pila durante todo el periodo (1157-1230). Pero es preciso hacer algunas matizaciones, ya que sólo confirmarán de este modo aquellos que por su reconocido prestigio y poder son fácilmente individualizables, como es el caso de los condes ${ }^{23}$.

A medida que avanzaba la organización linajística el empleo del patronímico fue fosilizándose hasta convertirse, con el tiempo, en el apellido inmutable generación tras generación. Este hecho, sin duda, recordaba a los antepasados más antiguos e insignes y era un mecanismo utilizado para vincularse de manera directa con ellos y subrayar su ascendencia ilustre ${ }^{24}$.

El porcentaje del uso del nombre de dos elementos es menor entre las mujeres. Es cierto que en la mayor parte de las ocasiones aparecen en la documentación junto a sus padres o esposos y tal vez por ello solo utilizan el nombre de pila; no obstante en los diplomas privados que emiten en solitario, suelen incluir su patronímico, tal vez porque están disponiendo de los bienes que han heredado de la familia y es un modo de identificarse como integrantes de la misma.

Este comportamiento nobiliario con respecto a los sistemas de identificación personal en ocasiones se importó a sus dependientes; es decir que algunos de los siervos o esclavos adoptaron el patronímico de su antiguo señor cuando eran liberados. Se han conservado pocos datos, pero parece que fue un procedimiento habitual; pues de este modo reivindicaban una filiación ficticia a un gran magnate del reino. Sin embargo consideramos que esta circunstancia se dio sólo con aquellos dependientes con los que el noble y su familia mantenían una especial relación de proximidad y afectividad, como los integrantes del servicio doméstico. Este parece ser el caso de María Ponce y García Ponce a los que algunos historiadores han considerado hijos de Ponce de Minerva y Estefanía Ramírez, aunque la documentación queda clara la relación que los unía con el matrimonio.

Se ha conservado la carta de libertad de María Ponce ${ }^{25}$, y una venta efectuada por García Ponce de unas casas que le habían concedido el conde Ponce y la condesa Estefanía,

22 HenNeBICHE, R. "Structures familiales et politiques aux IXeme siècle: en groupe familial du l'aristocratie franque", Revue Historique 538, (1981), pp. 289-333, p. 294.

23 Son innumerables los diplomas en los que se plasma este comportamiento, sin embargo aún hoy sabemos quiénes eran los individuos que confirman habitualmente sólo con el nombre de pila ya que destacan el cargo o la dignidad que ocupaban en la corte, lo que les hace fácilmente reconocibles.

24 Véase Pardo de Guevara y Valdés, E. Art. cit, pp. 31-35.

25 Casado Lobato, C. Colección diplomática del monasterio de Carrizo. Colección Fuentes y Estudios de Historia Leonesa, 28. Centro de Estudios e Investigación San Isidoro, León 1983, doc 36 Notum sit omnibus tam presentibus quam futuris, quod ego comitissa domina Stephania, iuxta quod Dominus per prophetam dixit: Dissolue colligationes impietatis, solue fasciculos deprimentes, dimitte eos qui confracti sunt liberos et omne homus eorum disrumpe. Absoluo te nomine Maria Pontii ab omni uinculo seruitutis propter animam comitis Pontii et propter remissionem peccatorum meorum tamen seruies mihi cunctis diebus quibus uixero postea uero quam uitam finiero corporis morte perge ubi uolueris cum libertate et securitate et ad quem dominum elegerit cor tuum. 
en la que se sobrentiende su condición ${ }^{26}$. Las palabras con las que el matrimonio condal se dirige a ambos, traslucen la afectividad que les unía y que, probablemente, influyó para que María y García adoptaran el patronímico de don Ponce de Minerva. Este comportamiento antroponímico marca la pertenencia ficticia a una familia, destinada a lograr el reconocimiento social. Desafortunadamente no se puede reconstruir la descendencia de estos individuos y, por tanto, se desconocen los usos antroponímicos que utilizaron.

\section{c) antropónimo + Nomen paternum + topónimo}

A medida que avanza el siglo XII, se hace más frecuente la incorporación de partículas topónimas al sistema de identificación personal. Numerosos personajes adoptaron estos topónimos, que hacen referencia a su origen, al lugar donde tenían su señorío o al territorio en el que ostentaban el poder.

En numerosas ocasiones los topónimos fueron adoptados como elementos de diferenciación por magnates homónimos y coetáneos. Son numerosos los ejemplos, aunque uno de los más significativos es el caso de Ponce de Cabrera y Ponce de Minerva. Ambos dignatarios confirman simultáneamente numerosos diplomas regios entre 1157 y 1164 , en todos ellos intentaban individualizar su persona. Ponce de Cabrera confirmaba añadiendo como distintivo su dignidad condal y el oficio palatino que ocupaba - comes Pontius, maiordomus regi ${ }^{27}$-, mientras Ponce de Minerva incluía su lugar de procedencia - Pontius de Menerua ${ }^{28}$. La situación cambió cuando falleció Ponce de Cabrera ${ }^{29}$. A partir de entonces y tras recibir la dignidad condal, Ponce de Minerva confirma sólo con el nombre de pila - comes Poncius - ya que había desaparecido la posibilidad de confundir a ambos

26 Ibid., doc 63. Ego Garcias Pontii facio cartam donationis y uenditionis uobis domne Tarisie, Dei gratia abbatisse de Carriço, omni conuentui eiusdem loci, de casis illis quas mihi dedit comes Pontius et comitissa domna Stephania pro animabus suis, que sunt in Legione, in loco prenominato Sanctus Andreas de Requexuelo, in barrio de Falcon. Como pago a estas casas solicita dos iugadas en Grulleros y Argavallones, ambos lugares vinculados al patrimonio familiar por donación regia. Este hecho nos hace sospechar sobre el parentesco que une a García Ponce con Ponce de Minerva y Estefanía Ramírez puesto que los hijos de la pareja también entregaron al monasterio de Carrizo las casas que habían heredado de su padre el conde Ponce. Estas referencias patrimoniales nos pueden llevar a pensar que García Ponce era también hijo de la pareja, pero el hecho de que no aparezca junto a los hijos del matrimonio - Ramiro, María y Sancha - en ningún documento y que en la venta de las casas a la que nos venimos refiriendo no explicite su parentesco, nos hace pensar que no se trata de un hijo del matrimonio, sino de un personaje próximo a la pareja, probablemente un servidor liberado que ha adoptado el patronímico de su señor.

27 Existe una pequeña controversia acerca de la fecha en la que Ponce de Cabrera obtuvo la dignidad condal. Recuero Astray afirma que fue en 1141, mientras que Fernández-Xesta asegura que fue nombrado conde entre los meses de marzo y abril de 1142, FERnÁNDEZ-XeSTA, E. Un magnate catalán en la corte de Alfonso VII.Comes Poncius de Cabreira, prinçeps Çemore. Prensa y ediciones Iberoamericanas, S.L.Madrid, 1991. pp. 116-117.

28 Fernández Catón, J.Mª. Colección documental de la catedral de León, (775-1230), V (1109-1187), Colección: Fuentes y Estudios de Historia Leonesa, 45. Centro de Estudios e Investigación San Isidoro, León 1990, docs. 1509, 1511.

29 No se ha determinado con exactitud la fecha de su muerte, aunque podría oscilar entre marzo de 1162 y septiembre de 1164 . 
magnates. Ambos dignatarios tuvieron hijas que se llamaron Sancha Ponce, pero ninguna de ellas incorporó el topónimo para denominarse ${ }^{30}$.

En otras ocasiones resulta casi imposible distinguir a dos personajes que comparten el mismo nombre y patronímico, como sucede con Fernando Fernandes de Bragança y Fernando Fernández (de Cabrera). El de Bragança añade la partícula toponímica que permite diferenciarlo en pocas ocasiones ${ }^{31}$, mientras que Fernando Fernández (de Cabrera) lo hace de manera excepcional, lo que dificulta en gran medida la identificación de ambos personajes, cuando aparecen en solitario. Quizá el ejemplo más gráfico de este problema sea un documento fechado el 23 de febrero de 1198 en Bragança por el que Fernando Fernandi dona determinados bienes al monasterio de Nogales, situado en tierras zamoranas donde los Bragança y los Cabrera tenían intereses. Viendo que el documento se firmó en Bragança se podría pensar que el donante era el señor de Bragança, no obstante, se identifica como filius Fernandi Ponti maiorinis et nepos comitis Pontii de Cabrera, lo que deja clara su filiación ${ }^{32}$.

Otros individuos de las parentelas estudiadas que incorporaron un topónimo a su nombre y patronímico fueron Rodrigo Fernández de Valduerna, que, en ocasiones utilizó también, el topónimo “de Cabrera”, además de Rodrigo Pérez de Villalobos o Juan Fernández de Limia, todos ellos hacen referencia al lugar en el que detentaban el poder.

\section{d) Cognomen}

Tras observar las parentelas estudiadas se aprecia un escaso éxito del cognomen a partir del siglo XI, cuando comienza a implantarse de manera definitiva el nombre de dos elementos. No obstante, si se amplia la escala de nuestro estudio se detecta una mayor utilización del cognomen en la región asturiana, aunque, como hemos destacado, el elemento toponímico pueda considerarse en ocasiones como cognomento personal, frecuente en la nobleza leonesa. Suárez Beltrán afirma que a partir de la segunda mitad del siglo XII en Asturias aumenta el uso de cognomina lo que se relaciona con el despegue de la vida urbana y la individualización personal de la burguesía ${ }^{33}$. Asimismo, el fenómeno puede registrarse también en el estamento nobiliar donde aparecen individuos como Diego Abregón o Gonzalo Gebelín ${ }^{34}$. Sin duda, el sobrenombre era un elemento identificador de gran importancia, ya que identificaba a la persona durante toda su vida; incluso se conservaba más allá de las fronteras del reino del que se era originario, como sucedió con Pero

30 Sancha Ponce, la hija de Ponce de Cabrera casó con Vela Gutiérrez, mientras que Sancha Ponce, la hija de Ponce de Minerva, que casó con Pedro García de Lerma.

31 Un diploma emitido en Villafáfila en 1220 está confirmado por Fernandus Fernandi de Bregancia y Fernando Fernandez, maiordomo regis, tenente Beneventum, Senabriam et Cabreram. GonZÁLEZ, J. Alfonso IX, vol II, doc 403. En este caso ambos dignatarios incluyen elementos toponímicos que permite identificarlos, pero en la mayor parte de las ocasiones no ocurre así.

32 NOTA.

33 SuÁrez Beltrán, S., "Notas al sistema antroponímico asturiano en los siglos X al XII," MARTíneZ Sopena, P. (coord.), Antroponimia y sociedad. Sistemas de identificación hispano- cristianos en los siglos IX a XIII, Valladolid 1995, pp. 121-132.

34 SuÁREZ FERNÁNDEZ, A. "Orígenes y ascensión de un linaje nobiliario asturiano: Los Álvarez de Noreña" Asturiensia Medievalia, 8, (1995-1996), pp. 239-262. 
Pais de Maia ${ }^{35}$, o alferes, que se trasladó a León conservando el cognomen que le habían puesto en Portugal por el largo tiempo que había ocupado el cargo en la corte de Alfonso Enríquez. Así, en la documentación leonesa aparece como Petrus Pelagii de Portugal, signifer ${ }^{36}$, Petrus Pelagii de Thoronio, signifer vocatus, Petrus Pelagii signifer dictus ${ }^{37}$. Además de este tipo de cognomina, aparecen otros que responden a las características físicas de los propios individuos, aunque en el periodo estudiado son todavía escasos. El ejemplo más significativo es el de Rodrigo Fernández de Valduerna que en numerosas ocasiones aparece como, el feo.

\section{B. EL PREDOMINIO DE LOS USOS ANTROPONÍMICOS LEONESES EN LA NOBLEZA FORÁNEA ESTABLECIDA EN LEÓN}

Resulta sumamente interesante el comportamiento antroponímico de los magnates procedentes de los reinos orientales que se asentaron en León, puesto que adoptaron el sistema de identificación personal leonés. En los casos de Ponce de Cabrera y Ponce de Minerva el sistema antroponímico leonés arrolla a los usos catalanes.

A pesar de estar fuertemente arraigados en las ramas de la familia asentadas en su lugar de origen, las costumbres onomásticas de los vizcondes de Gerona y Urgell no tuvieron demasiada repercusión en tierras leonesas. Algunos nombres como Giraldo se perdieron rápidamente y Ponce tampoco tuvo demasiada proyección. Asimismo, Ponce de Minerva que había casado con Estefanía Ramírez, asumió la onomástica propia de la familia de su esposa, llamando a sus hijos Ramiro, Sancha y María y en ningún caso utilizó los nombres del Languedoc, de donde era oriundo. Resulta significativo que su primogénito recibiera el nombre del abuelo materno, el conde Ramiro Froilaz, lo que representa un claro ejemplo de cómo la antroponimia fue utilizada para vincularse a la parentela preponderante, los Flaínez, obviando cualquier referencia a la familia paterna, que no tuvo participación en la escena política leonesa. En ambos casos los nombres de pila catalanes, que resultaban en cierta medida exóticos, no tuvieron demasiada repercusión en la sociedad leonesa.

El recorrido antroponímico de la familia de Ponce de Cabrera es sumamente revelador. En varios documentos leoneses en los que aparece el magnate catalán, es denominado Ponce Giraldo ${ }^{38}$; pero a raíz de que se le otorga la tenencia de Cabrera, añade este elemento toponímico que hace referencia al lugar donde ejerce su poder y eliminó al patronímico.

35 Calderón Medina, I. Cum magnatibus regni mei. La nobleza y la monarquia leonesa durante los reinados de Fernando II y Alfonso IX de León, CSIC, Madrid, 2011. (en prensa).

36 GonZÁlez, J. Regesta de Fernando II, Instituto Jerónimo Zurita. Madrid, 1943, p. 423.

37 Recuero Astray, M. (dir.) Documentos medievales del reino de Galicia: Fernando II (1157-1187), Xunta de Galicia. Santiago de Compostela 2000, docs. 201, 213.

38 FERnÁndez Flórez, J. A. Colección diplomática del monasterio de Sahagún, IV,(1110-1199) Colección: Fuentes y Estudios de Historia Leonesa, 38. Centro de Estudios e Investigación San Isidoro, León 1991. Doc 1329. Fuit contencio inter comitem Poncium Gueraldi et tercium Dominicum. 
A partir de entonces, aparecerá como Ponce de Cabrera ${ }^{39}$. Parece que el conde Ponce utilizó este topónimo en referencia a esta importante tenencia que ostentó durante largo tiempo, aunque no se puede olvidar que Ponce pertenecía a los Cabrera catalanes, por lo que es posible que importara con él esa denominación que indicaba su origen.

Decíamos en líneas anteriores que el elemento toponímico fue utilizado por determinadas personas para individualizarse y no se convirtió en un elemento que identificara a la parentela; es decir que en ningún caso se encuentran referencias a la casa de los Cabrera en León, sino que sólo algunos de sus miembros asumieron el nombre de una tenencia vinculada a la familia durante generaciones ${ }^{40}$. Algunos de los descendientes de Ponce de Cabrera incorporaron esta partícula toponímica, no obstante llama la atención que ninguno de sus hijos adoptara esta denominación ${ }^{41}$; sin embargo, sí lo hicieron algunos de sus nietos. Así Rodrigo Fernández, el de Valduerna ${ }^{42}$, se intitula en ciertas ocasiones, aunque de manera minoritaria, Rodrigo Fernández de Cabrera ${ }^{43}$. Pedro Ponce de Cabrera, que se erigió en cabeza de la parentela en torno a 1230 y logró casar con Aldonza Alfonso, hija ilegítima de Alfonso IX, adoptó también el toponímico ${ }^{44}$.

El nombre de pila "Ponce", de carácter claramente foráneo, se fosilizó en la descendencia de Pedro Ponce de Cabrera ${ }^{45}$ y Aldonza Alfonso. Fernando, Juan y Pedro, sin desdeñar el patronímico, Pérez, añadieron Ponce a modo de apellido, sin duda para vincular su parentela con el antepasado más ilustre: el conde Ponce de Cabrera, mayordomo del emperador. A finales del siglo XIII cuando una de las ramas de la familia se asientó en Andalucía, añadió la partícula toponímica “de León”, que se perpetuará en la familia. De este modo se señalaba, por una parte su origen y, por otra, se subrayaba su ascendencia

39 No se han conservado demasiados diplomas en los que el conde Ponce sea el destinatario de una donación regia, sino que la mayor parte de las apariciones en las cartas es como confirmante. Las signa como comite Poncius. No obstante en los ejemplos conservados como en el que recibe de manos de Alfonso VII la villa de Almorecir, se dirige a él como ad uos comite domno Ponz de Cabrera-RAH Salazar y Castro I-38, fol 281v$282 v$. Asimismo sus descendientes se referirían a él con el apelativo toponímico en varias ocasiones, como la donación de la villa de Granucillo al monasterio de Nogales Ego igitur predictus Fernandus Fernandi, filius Fernandi Pontii maioris et nepos comitis Pontii de Cabrera, CAVERo DOMÍNGuEZ, G. Colección Documental del Monasterio de San Esteban de Nogales (1149-1498), Colección: Fuentes y Estudios de Historia Leonesa, 91. Centro de Estudios e Investigación San Isidoro, León 2001, doc 25.

40 Los Flaínez no incorporaron a su sistema antroponímico ningún elemento toponímico que hiciera referencia a su lugar de procedencia o sobre el que ejercían el poder; no obstante en la memoria colectiva pervivió la vinculación de algunos de estos personajes con la Tierra de Campos.

41 No se ha conservado ningún diploma en que los hijos del conde Ponce adopte el elemento toponímico, a pesar de que estuvieron al frente de la tenencia de Cabrera.

42 Resulta complicado establecer la filiación exacta de este personaje. Sabemos que fue hijo de uno de los Fernando Ponce, sin embargo no podemos discernir si se trata de Fernando Ponce el mayor o el menor. En cualquier caso se trata de un nieto de Ponce de Cabrera.

43 GonZÁlez, J. Alfonso IX, vol. II, Instituto Jerónimo Zurita, Madrid, 1944, doc. 294.

44 Sciant presentes et posterit quod nos dommus Petrus Poncii de Cabrera et domna Aldonça Alfonsi, Cavero Domínguez, G. Colección Documental del Monasterio de San Esteban de Nogales (1149-1498), Colección: Fuentes y Estudios de Historia Leonesa, 91. Centro de Estudios e Investigación San Isidoro, León 2001, doc 51 .

45 Ponce es el patronímico de este hombre que era hijo de Ponce Vela. 
regia, aunque fuera por línea bastarda, para enaltecer su prestigio social ${ }^{46}$. Este comportamiento de fosilización del apellido y la transmisión vertical del mismo, indica que el avance de los esquemas agnaticios en la organización interna de la aristocracia leonesa.

\section{CONCLUSIONES}

El análisis del sistema antroponímico de la nobleza leonesa plenomedieval es un elemento revelador de la evolución de la estructura interna de las familias aristocráticas. Durante el periodo estudiado podemos observar la lenta evolución de este proceso atendiendo a varios indicadores. El hecho que los nombres de pila asociados a la familia se transmitan de forma bilateral, tanto por la línea paterna como la materna, indica que la organización interna respondía a esquemas cognaticios; sin embargo, el ejemplo de la fosilización del nombre de pila "Ponce", utilizado como apellido y transmitido generación tras generación desde mediados del siglo XIII, indica un importante avance de las estructuras agnáticas.

La antroponimia, sin duda, fue un elemento de creación de identidad y de memoria genealógica nobiliaria de primera magnitud, ya que el simple hecho de recibir el nombre en el momento del bautismo identificaba al recién nacido como miembro de su grupo parentelar. Asimismo, el sistema de identificación personal fue un elemento de creación de memoria genealógica, que avanzado el siglo XIII fue empleado para destacar la antigüedad y el prestigio social de la familia.

46 Carriazo Rubio, J.L. La memoria del linaje. Los Ponce de León y sus antepasados a fines de la Edad Media. Universidad de Sevilla, Sevilla, 2002, pp. 33-37. El autor no elabora un estudio onomástico del linaje sino que destaca este comportamiento relacionándolo primero con la unión de Pedro Ponce con Aldonza Alfonso, que culmina el ascenso del linaje desde tiempos de Ponce de Cabrera. A partir de entonces, su descendencia, sin desdeñar el patronímico, utiliza Ponce como apellido. Por otra parte el traslado de una parte de la familia a un nuevo ámbito geográfico motivó la adición de un elemento toponímico, “de León” que se perpetuaría en la familia y que además señalaba la ascendencia regia, aunque fuera por vía ilegítima. 